\title{
PRINCIPAIS CAUSAS DE CONDENAÇÃO AO ABATE DE AVES EM MATADOUROS FRIGORÍFICOS REGISTRADOS NO SERVIÇO BRASILEIRO DE INSPEÇÃO FEDERAL ENTRE 2006 E 2011
}

\section{MAIN CAUSES OF CONDEMNATION IN POULTRY SLAUGHTERHOUSES REGISTERED IN BRAZILIAN FEDERAL INSPECTION SERVICE FROM 2006 TO 2011}

\author{
Adriana Aguiar Oliveira ${ }^{*}$ \\ Maria Auxiliadora Andrade ${ }^{2}$ \\ Paulo Marcel Armendaris ${ }^{3}$ \\ Pedro Henrique Salgado Bueno ${ }^{4}$
}

${ }^{1}$ Departamento de Inspeção de Produtos de Origem Animal - DIPOA. Secretaria de Defesa Agropecuária SDA. Ministério da Agricultura, Pecuária e Abastecimento - MAPA. Brasília, DF, Brasil.

${ }^{2}$ Departamento de Medicina Veterinária. Escola de Veterinária e Zootecnia. Universidade Federal de Goiás, Goiânia, GO, Brasil.

${ }^{3}$ Laboratório Nacional Agropecuário em Porto Alegre - LANAGRO/RS. Ministério da Agricultura, Pecuária e Abastecimento - MAPA. Porto Alegre, RS, Brasil.

${ }^{4}$ Unidade Técnica Regional de Agricultura, Pecuária e Abastecimento em Varginha. Superintendência

Federal de Agricultura, Pecuária e Abastecimento de Minas Gerais - SFA/MG. Varginha, MG, Brasil.

*Autora para Contato - oliveiravet@yahoo.com.br

\section{Resumo}

A indústria avícola no Brasil, bem como o consumo interno e exportações de carne de frango têm apresentado um expressivo crescimento. O Serviço de Inspeção Federal é responsável pela inspeção sanitária ao abate de aves e registra rotineiramente as lesões ou doenças identificadas no Sistema de Informação Gerenciais do Serviço de Inspeção Federal (SIGSIF). O objetivo deste estudo foi identificar as principais causas de condenação de aves em matadouros-frigoríficos registradas no Serviço de Inspeção Federal a partir dos dados lançados no sistema SIGSIF entre 2006 e 2011. O índice de condenações observado neste período foi de $5,99 \%$, sendo que as principais causas foram: contaminação $(1,80 \%)$, contusão/lesões traumáticas $(1,57 \%)$, dermatoses $(0,74 \%)$ e celulite $(0,50 \%)$. Diferenças regionais foram observadas na ocorrência das condenações e apenas no caso das dermatoses observou-se um comportamento sazonal. O SIGSIF constitui uma importante fonte de informação sobre as causas de condenações ao abate de aves, podendo ser uma ferramenta útil para a avaliação dos fatores causais e para a proposição de medidas de prevenção ou mitigação de riscos. Palavras-chave: abate; aves; condenação; doenças; tecnopatias.

\begin{abstract}
The poultry industry in Brazil as well as the domestic consumption and exportation of poultry have experienced significant growth. The Federal Inspection Service is responsible for the sanitary inspection of poultry slaughter, and it routinely records injuries or illnesses that have been identified in the Management Information System of the Federal Inspection Service (SIGSIF). The aim of this study was to evaluate the main causes of condemnation in poultry slaughterhouses registered in the Federal Inspection Service from data entered into the SIGSIF system from 2006 to 2011. The total rate of condemnations observed during this period was $5.99 \%$, and the major causes were contamination $(1.80 \%)$, contusion /traumatic injuries $(1.57 \%)$, dermatosis $(0.74 \%)$ and cellulitis $(0$,
\end{abstract}


$50 \%$ ). Regional variations were observed in the occurrence of condemnations, and only in case of dermatosis a seasonal behavior was observed. The SIGSIF is an important source of information concerning the causes of condemnations in poultry slaughter and can be a useful tool for assessing the causes and proposing measures to prevent or mitigate risks.

Keywords: condemnation; diseases; poultry; slaughter; traumatic injuries.

Enviado em: 11 março 2013

Aceito em: 18 novembro 2015

\section{Introdução}

A qualidade da carne de frango produzida no país é inspecionada e fiscalizada, no âmbito federal, pelo Serviço de Inspeção Federal (SIF), que atua diretamente em abatedouros frigoríficos, cujas funções são inspecionar e fiscalizar o processo de produção da carne ofertada à população visando garantir sua qualidade higiênico-sanitária. Esta é uma atividade privativa do Departamento de Inspeção de Produtos de Origem Animal (DIPOA), sempre que se tratar de produtos destinados ao comércio interestadual ou internacional, e abrange inspeção "ante" e "post mortem" dos animais, recebimento, manipulação, transformação, elaboração, preparo, conservação, acondicionamento, embalagem, depósito e rotulagem, de quaisquer produtos e subprodutos ${ }^{(1)}$.

Entre as diversas atividades realizadas pelo médico veterinário oficial incluem-se a identificação, caracterização e registro por meio de mapas nosográficos dos processos patológicos dos animais abatidos, bem como da ocorrência de situações antes e durante o processo de abate que possam gerar a perda da qualidade higiênico-sanitária da carne de frango produzida. A Portaria SDA $\mathrm{n}^{\circ} 210$, de 10 de novembro de 1998, que aprova o Regulamento Técnico da Inspeção Tecnológica e HigiênicoSanitária de Carne de Aves, determina o registro mensal de destinação das aves abatidas passadas pela inspeção final (Anexo VIII), com o registro do total de aves abatidas, total de aves mortas e as causas de condenação ${ }^{(2)}$.

O Sistema de Informações Gerenciais do Serviço de Inspeção Federal (SIGSIF) é um sistema informatizado, criado em 2003, em que são registradas as lesões identificadas pelo SIF ao abate. Estes registros de condenação são reconhecidos como uma relevante fonte de informação sobre doenças nos animais e também para a avaliação da condição sanitária das explorações pecuárias. Além de permitir a identificação de doenças subclínicas, podem também quantificar a gravidade de lesões que representam as manifestações destas doenças ${ }^{(3,4,5)}$.

Manifestações sugestivas de doenças infectocontagiosas ou parasitárias, incluindo zoonoses ou lesões indicativas de deficiências tecnológicas no manejo dos animais no pré-abate e durante o abate podem ocorrer nas aves abatidas. Estas lesões, verificadas durante o abate, normalmente cursam com um amplo espectro de diagnósticos prováveis, cabendo ao médico veterinário oficial o julgamento quanto à patologia base e destino das carcaças, com base na anamnese do lote e inspeção visual dos achados patológicos, podendo solicitar o auxílio de exames laboratoriais complementares ${ }^{(1,2)}$.

Em diversos países, as taxas de condenação de carcaças de aves variaram de 0,41 a $4,13 \%{ }^{(3,6-9)}$. Já alguns estudos realizados no Brasil, principalmente na região sul, relatam taxas de condenação variando de 0,17 a $8,97 \% \%^{(10-13)}$.

Diversos trabalhos ${ }^{(3,5,6,14,15)}$ destacam como principais causas de condenação ao abate de aves a celulite, a contaminação e a contusão/fratura, entre outras. Estas lesões apresentam crescente importância na indústria avícola devido às modificações nas técnicas e tecnologias de criação e manejo, assim como no processamento industrial das aves ao longo do tempo ${ }^{(16)}$. Entretanto, apesar da crescente importância das tecnopatias, a relevância e magnitude das doenças veiculadas por alimentos não podem ser esquecidas, a exemplo das salmoneloses, Escherichia coli O157:H7, pois representam grande risco à saúde do consumidor ${ }^{(17)}$.

Considerando o exposto, o presente estudo teve como objetivo avaliar o Sistema de Informações Gerenciais do Serviço de Inspeção Federal - SIGSIF quanto às principais causas de condenação em matadouros-frigoríficos de aves registradas. 


\section{Material e Métodos}

Os dados de doenças ou lesões identificadas em estabelecimentos sob Inspeção Federal e que abatem aves são lançados no SIGSIF com frequência diária ou mensal, conforme conveniência da Inspeção Federal no estabelecimento. As informações são armazenadas no banco de dados do sistema, podendose emitir relatórios para avaliação dos dados.

Para este estudo, foram coletados os dados secundários de condenação e abate de aves em estabelecimentos registrados no Serviço de Inspeção Federal - SIF, no período de 2006 a 2011, diretamente da base de dados central do SIGSIF, sob responsabilidade do Departamento de Inspeção de Produtos de Origem Animal - DIPOA. Os dados foram coletados em 05 de junho de 2012 e as variáveis tabuladas foram: "quantidade condenada", "nome do diagnóstico", "UF", "mês", "ano", "destino da condenação" e "número de aves abatidas".

Previamente à análise dos dados, realizou-se a limpeza manual das inconsistências encontradas, utilizando-se como referência a variável "nome do diagnóstico" e calculando-se o percentual de inconsistências (número de condenações inconsistentes/total de condenações). Foram retiradas das análises as inconsistências como diagnóstico não compatível com a espécie ou diagnósticos incompreensíveis.

Foi realizada a análise descritiva dos dados, calculando-se frequências (\% causa de condenação/total de condenações), taxas (\% condenações/aves abatidas), médias de condenação por ano e o índice de ocorrência de condenação (IOC) por 1.000 aves abatidas, conforme proposto por Moretti et al. ${ }^{(5)}$. Para as comparações, foi calculado o qui-quadrado para variáveis categóricas ou Anova/KruskallWallis para comparação de médias, considerando-se um nível de significância de 5\%, com o auxílio do software EpiInfo versão 3.5.1 e a regressão linear simples utilizando o software Microsoft Office Excel 2007.

\section{Resultados e Discussão}

No período de 2006 a 2011, o percentual de inconsistências encontrado foi de $0,03 \%$ (432.066/1.613.079.199). Mesmo não sendo considerado um percentual alto, quando comparado ao volume de condenações, estas foram retiradas das análises.

Ao se trabalhar com dados secundários, deve-se sempre avaliar a possibilidade de inconsistências na informação, muitas vezes ocasionadas por erros de lançamento dos dados. O sistema SIGSIF, criado em 2003, não possui uma ferramenta de validação dos diagnósticos prováveis por espécie animal, o que permite lançamentos errôneos de registros doenças ou lesões identificadas ao abate, como verificado neste estudo. Desta forma, é importante a avaliação periódica dos lançamentos no banco de dados visando minimizar erros. Adicionalmente, está sendo desenvolvido um novo projeto de sistema informatizado para gerenciamento do Serviço de Inspeção Federal, em que se espera a inclusão de ferramentas de validação de informações antes do lançamento.

No Brasil, a taxa de condenações totais e parciais ao abate de aves, calculada para o período de 2006 a 2011, foi de 5,99\%, sendo que o ano de 2008 apresentou significativamente maior taxa (Tabela 1). Destas, $85 \%$ corresponderam a condenações parciais e $15 \%$ a condenações totais.

A Figura 1 demonstra a distribuição da taxa de condenação ao longo dos anos. Apesar de um ligeiro aumento na taxa de condenações no período, esta apresentou baixa correlação linear $\left(\mathrm{R}^{2}=0,22\right)$.

Quando se avaliam as condenações por mês, verifica-se que não há diferença estatisticamente significativa entre a média de condenações $(\mathrm{p}=0,6468)$ e o índice de ocorrência de condenações $(\mathrm{p}=0,5389)$ ao longo do ano (Tabela 2$)$.

A distribuição das condenações por região (Figura 2) demonstra que a maior proporção de condenações ocorre nas regiões Sul (61\%), Sudeste (21\%) e Centro-Oeste (17\%), ou seja, nas regiões que concentram o maior número de empresas frigoríficas e, consequentemente, maior volume de abate de aves. 
Tabela 1: Condenações de aves ao abate em estabelecimentos inspecionados pelo Serviço de Inspeção Federal (SIF), Brasil, de 2006 a 2011

\begin{tabular}{lccc}
\hline Ano & $\mathbf{N}^{\circ}$ de condenações & $\mathbf{N}^{\circ}$ animais abatidos & Taxa de condenação (\%)* \\
\hline 2006 & 196.284 .436 & 3.775 .358 .141 & 5,20 \\
2007 & 248.534 .775 & 4.137 .069 .442 & 6,01 \\
2008 & 289.909 .414 & 4.551 .190 .830 & 6,37 \\
2009 & 279.923 .292 & 4.496 .993 .296 & 6,22 \\
2010 & 295.798 .660 & 4.794 .314 .669 & 6,17 \\
2011 & 302.196 .556 & 5.150 .695 .204 & 5,87 \\
\hline Total & 1.612 .647 .133 & 26.905 .621 .582 & 5,99 \\
\hline
\end{tabular}

$* \mathrm{X}^{2}$ de tendência linear $=1033,122 ; \mathrm{p}<0,000001$

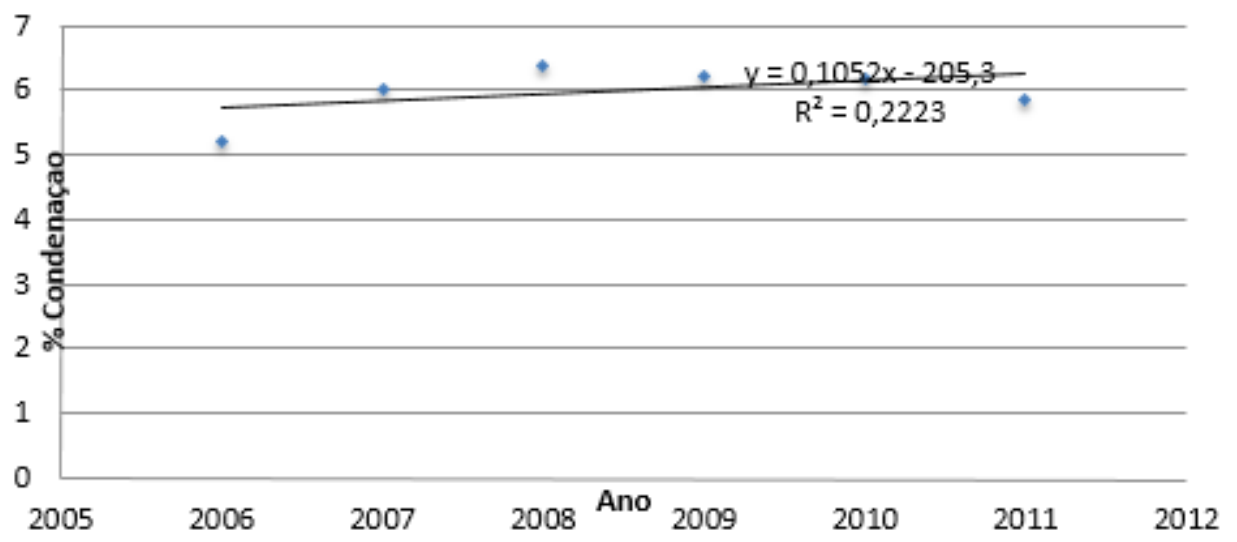

Figura 1: Taxa de condenação de aves ao abate por ano, Brasil, de 2006 a 2011.

Tabela 2: Média de condenações e indice de ocorrência de condenações (IOC) médio ao abate de aves, por mês, Brasil, de 2006 a 2011

\begin{tabular}{lcc}
\hline Mês & Média de condenações* & IOC médio** $^{* *}$ \\
\hline Jan & 368.807 .676 & 59 \\
Fev & 341.340 .213 & 59 \\
Mar & 386.939 .945 & 59 \\
Abr & 349.248 .454 & 59 \\
Mai & 376.912 .201 & 59 \\
Jun & 365.352 .408 & 62 \\
Jul & 387.068 .637 & 63 \\
Ago & 388.363 .857 & 62 \\
Set & 372.850 .169 & 60 \\
Out & 391.492 .636 & 61 \\
Nov & 374.483 .568 & 59 \\
Dez & 381.410 .501 & 55 \\
\hline Total & 4.484 .270 .264 & 60 \\
\hline *ANOVA - Teste $\mathrm{F}=0,7923, \mathrm{p}=0,6468 ; *$ ANOVA - Teste $\mathrm{F}=0,9075, \mathrm{p}=0,5389$
\end{tabular}




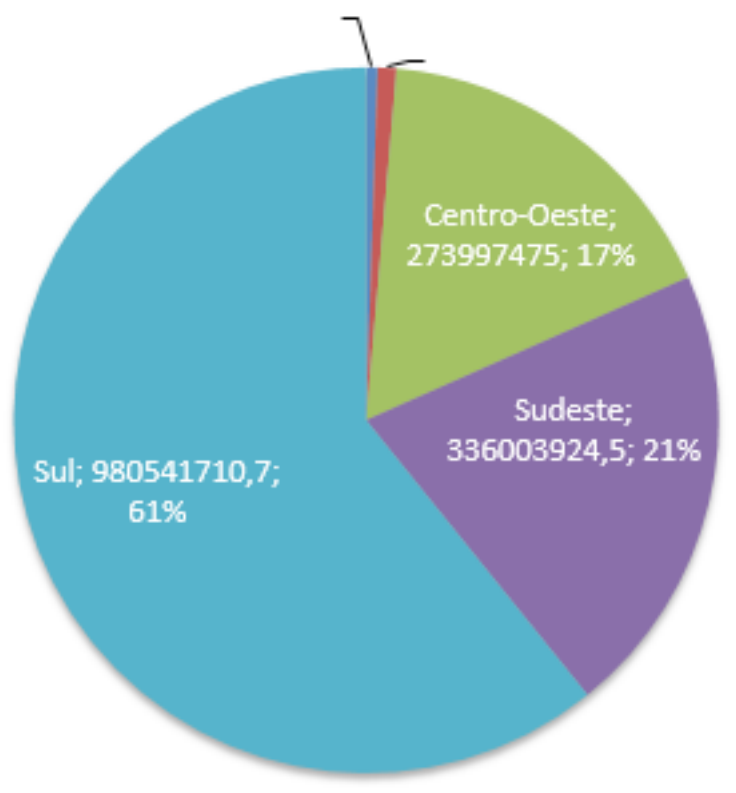

Figura 2: Condenações ao abate de aves por região, Brasil, de 2006 a 2011.

Entretanto, quando se calcula a taxa de condenações por região, verificam-se taxas significativamente maiores na região centro-oeste $(7,85 \%)$, seguida pelas regiões sul $(5,85)$ e sudeste $(5,47)$ (Tabela 3$)$.

Tabela 3: Número, média e taxa de condenação de aves ao abate por região, Brasil, de 2006 a 2011

\begin{tabular}{lccc}
\hline Região & $\begin{array}{c}\mathbf{N}^{\circ} \text { de } \\
\text { condenações }\end{array}$ & $\begin{array}{c}\text { Média de condenações } \\
\text { por ano }\end{array}$ & $\begin{array}{c}\text { Taxa de condenação } \\
(\mathbf{\%})^{*}\end{array}$ \\
\hline Norte & 8.353 .351 & 1.455 .031 & 5,22 \\
Nordeste & 13.750 .672 & 2.546 .417 & 3,91 \\
Centro-oeste & 273.997 .475 & 45.666 .246 & 7,85 \\
Sudeste & 336.003 .924 & 56.334 .575 & 5,47 \\
Sul & 980.541 .711 & 163.423 .618 & 5,85 \\
\hline Total & 1.612 .647 .133 & 269.425 .887 & 5,99 \\
\hline${ }^{*}$ p $<0,000001$ & & &
\end{tabular}

A taxa geral de condenações observadas neste estudo (5,99\%) foi superior à observada nos estudos de Ansong-Danquah ${ }^{(3)}$, que relatou, no Canadá, uma taxa geral de condenação de carcaças de aves no período de 1980 a 1985 variando de $1,96 \%$ a $1,72 \%$, e Drain et al. ${ }^{(8)}$, e Whiting et al. ${ }^{(9)}$, que relataram $1,7 \%$ de condenação em Manitoba, no Canadá. Neste mesmo país, Herenda \& Jakel ${ }^{(6)}$, relataram diferenças no percentual de condenação de carcaças entre diferentes sistemas de criação e manejo, variando de $0,94 \%$ a $5,23 \%$.

Alguns estudos realizados no Brasil apresentam percentuais de condenação mais elevados, corroborando os achados deste trabalho. No Sul do Brasil, Paschoal et al. (13) e Ferreira et al. ${ }^{(12)}$ relataram, respectivamente, $7,89 \%$ e $4,74 \%$ de condenações parciais. No Estado de Goiás, foram relatados $8,3 \%$ e $3,6 \%$ de condenações totais em dois abatedouros ${ }^{(15)}$.

Segundo Ansong-Danquah ${ }^{(3)}$, as diferenças nas taxas de condenações encontradas no Brasil 
comparadas a outros países devem ser avaliadas cautelosamente, visto que existem diferenças nas legislações que regulamentam o abate e a inspeção da carne de animais de produção entre os países, bem como mudanças nas legislações dos países ao longo dos anos, em relação aos critérios de julgamento e destinação de carcaças ou partes animais.

No Brasil, as legislações base para o julgamento e destinação de aves são o Decreto 30.691 de 29 de março de 1952 (RIISPOA) e a Portaria N. 210, de 10 de novembro de $1998^{(1,2)}$. Entretanto, a explicação para a grande diferença observada no percentual de condenação e nas principais causas de condenação estudadas por Santana et al. ${ }^{(15)}$, em dois abatedouros de Goiás, são apontadas como diferenças no manejo das granjas avícolas, como a densidade no lote, método de apanha e transporte, diferenças no volume de aves abatidas por dia e na velocidade de abate entre estabelecimentos, bem como deficiências na regulagem do equipamento de evisceração quando são abatidos lotes de diferentes pesos no mesmo dia.

A melhoria nas condições de bem estar dos animais e redução de estresse na criação, no transporte ao abatedouro e no pré-abate são apontados como fatores que reduzem a ocorrência de condenações de aves ao abate por patologias como celulites, dermatoses, lesões traumáticas ou a chegada de animais mortos ao estabelecimento frigorífico. Já a contaminação de carcaças devido a rupturas das vísceras durante os processos de evisceração poderiam ser reduzidas com a melhoria na regulagem dos equipamentos de evisceração em função do peso dos lotes e velocidade de abate ${ }^{(8,9,15,18-20)}$.

A ocorrência das condenações totais e parciais entre 2006 e 2011 não apresentou um padrão de aumento significativo ao longo do período, divergindo do observado por Armendaris ${ }^{(10)}$, que avaliou o total de achados patológicos incluído no SIGSIF no período de 2003 a 2005 e encontrou valores crescentes de aproximadamente $2,85 \%$ a 3,3\%. Entretanto, o período avaliado acima compreendeu aos três primeiros anos após a implantação do sistema SIGSIF.

No presente estudo, optou-se por excluir das análises o período inicial de implantação do SIGSIF (2003 a 2005) por considerá-lo um período de adaptação do Serviço de Inspeção Federal à utilização da ferramenta, com provável instabilidade na inserção de informações. Esta pode ter sido a causa da diferença observada entre os dois estudos.

Entre 2006 e 2011, as dez principais causas de condenação ao abate estão listadas na Tabela 4. Somadas, estas causas representam $92,3 \%$ do total de condenações no período. Destacam-se como principais causas de condenação contaminações $(1,80 \%)$, contusão/lesão traumática $(1,57 \%)$, dermatose $(0,74 \%)$ e celulite $(0,50 \%)$.

Tabela 4: Principais causas de condenação ao abate de aves, Brasil, de 2006 a 2011

\begin{tabular}{lccc}
\hline Causa de condenação & $\begin{array}{c}\mathbf{N}^{\circ} \text { de } \\
\text { condenações }\end{array}$ & $\begin{array}{c}\text { Frequência de } \\
\text { condenação (\%) }\end{array}$ & $\begin{array}{c}\text { Taxa de } \\
\text { condenação (\%)* }\end{array}$ \\
\hline Contaminação & 483.065 .489 & 30,0 & 1,80 \\
Contusão / Lesão traumática & 421.213 .038 & 26,1 & 1,57 \\
Dermatose & 200.121 .819 & 12,4 & 0,74 \\
Celulite & 134.466 .496 & 8,3 & 0,50 \\
Artrite & 101.371 .476 & 6,3 & 0,38 \\
Aerosaculite & 42.527 .781 & 2,6 & 0,16 \\
Aspecto repugnante & 35.282 .344 & 2,2 & 0,13 \\
Síndrome ascítica & 24.460 .981 & 1,5 & 0,09 \\
Caquexia & 23.283 .036 & 1,4 & 0,09 \\
Lesão supurada & 22.142 .861 & 1,4 & 0,08 \\
Demais causas & 124.711 .813 & 7,7 & 0,46 \\
\hline Total de condenações & 1.612 .647 .133 & 100,0 & 59,9 \\
\hline * O número total de aves abatidas no período de 2006 a 2011 utilizado para o cálculo da taxa de condenação \\
é 26.905.621.582.
\end{tabular}


As condenações por contaminação ocorreram em maior número nas regiões sul (64,2\%), centro-oeste $(18,5 \%)$ e sudeste $(17 \%)$. No entanto, a taxa de condenação demonstra que uma maior ocorrência de condenações por contaminação esteve presente na região centro-oeste $(2,56 \%)$, seguidas pelas regiões sul $(1,85 \%)$ e sudeste $(1,34 \%)$ (Tabela 5$)$.

Tabela 5: Número, frequência e taxa de condenações ao abate de aves devido à contaminação por Região, Brasil, de 2006 a 2011

\begin{tabular}{lccc}
\hline Região & $\begin{array}{c}\mathbf{N}^{\circ} \text { de } \\
\text { contaminação }\end{array}$ & $\begin{array}{c}\text { Frequência de } \\
\text { condenação (\%) }\end{array}$ & $\begin{array}{c}\text { Taxa de condenação } \\
(\%)^{*}\end{array}$ \\
\hline Norte & 1.128 .598 & $0,2 \%$ & 0,70 \\
Nordeste & 549.324 & $0,1 \%$ & 0,16 \\
Centro-oeste & 89.227 .486 & $18,5 \%$ & 2,56 \\
Sudeste & 82.068 .696 & $17,0 \%$ & 1,34 \\
Sul & 310.091 .385 & $64,2 \%$ & 1,85 \\
\hline Total & 483.065 .489 & $100 \%$ & 1,80
\end{tabular}

Em relação às contusões ou lesões traumáticas, embora as regiões sul e sudeste tenham apresentado proporcionalmente maiores percentuais de condenação, $52 \%$ e $32 \%$ respectivamente, as maiores taxas de condenação por estas causas foram verificadas nas regiões sudeste $(2,23 \%)$ e norte $(2,17 \%)$, diferindo estatisticamente das demais regiões (Tabela 6).

Tabela 6: Frequência e taxa de condenações ao abate de aves devido à contusões/lesão traumática por região, Brasil, de 2006 a 2011

\begin{tabular}{lccc}
\hline Região & $N^{\circ}$ de condenações & $\begin{array}{c}\text { Frequência de } \\
\text { condenação }(\%)\end{array}$ & $\begin{array}{c}\text { Taxa de condenação } \\
(\%)^{*}\end{array}$ \\
\hline Norte & 3.478 .106 & $1 \%$ & $2,17^{\mathrm{a}}$ \\
Nordeste & 4.348 .879 & $1 \%$ & 1,24 \\
Centro-oeste & 59.420 .165 & $14 \%$ & 1,70 \\
Sudeste & 136.797 .597 & $32 \%$ & $2,23^{\mathrm{a}}$ \\
Sul & 217.168 .291 & $52 \%$ & 1,30 \\
\hline Total & 421.213 .038 & $100 \%$ & 1,57 \\
\hline * a: não diferem - valor de $\mathrm{p}=0,1319$, demais p<0,05 & &
\end{tabular}

Quanto à dermatose, apenas a região sul foi responsável por $72 \%$ do registro desta causa de condenação, porém a região norte foi a que apresentou significativamente maior taxa de condenação ao abate $(0,97 \%)$, seguidos pela pelas regiões sul $(0,86 \%)$ e centro-oeste $(0,73 \%)$ (Tabela 7$)$.

A quarta maior causa de condenação ao abate foi a celulite. A região sul apresentou proporcionalmente o maior percentual de condenações; contudo, foi a região centro-oeste que apresentou significativamente a maior taxa de condenações por celulite (Tabela 8).

A ocorrência de condenações ao longo do ano apresentou diferença estatisticamente significativa apenas para dermatoses. Observou-se um aumento da média do IOC para dermatose, principalmente nos meses de junho a outubro, que são meses mais frios nos principais estados produtores no Brasil (Tabela 9). 
Tabela 7: Freqüência de condenações ao abate de aves devido a dermatoses por Região, Brasil, de 2006 a 2011

\begin{tabular}{lccc}
\hline Região & $\begin{array}{c}\mathbf{N}^{\circ} \text { de } \\
\text { condenações }\end{array}$ & $\begin{array}{c}\text { Frequência de } \\
\text { condenação (\%) }\end{array}$ & $\begin{array}{c}\text { Taxa de condenação } \\
(\%))^{*}\end{array}$ \\
\hline Norte & 1.549 .734 & $0,8 \%$ & 0,97 \\
Nordeste & 160.803 & $0,1 \%$ & 0,05 \\
Centro-oeste & 25.349 .043 & $12,7 \%$ & 0,73 \\
Sudeste & 28.996 .045 & $14,5 \%$ & 0,47 \\
Sul & 144.066 .194 & $72,0 \%$ & 0,86 \\
\hline Total & 200.121 .819 & $100 \%$ & 0,74 \\
\hline${ }^{*}$ p $<0,000001$ & & &
\end{tabular}

Tabela 8: Frequência e taxa de condenações ao abate de aves devido à celulite por região, Brasil, de 2006 a 2011

\begin{tabular}{lccc}
\hline Região & $\begin{array}{c}\mathbf{N}^{\circ} \text { de } \\
\text { condenações }\end{array}$ & $\begin{array}{c}\text { Frequência de } \\
\text { condenação (\%) }\end{array}$ & $\begin{array}{c}\text { Taxa de condenação } \\
(\%)^{*}\end{array}$ \\
\hline Norte & 186.125 & $0,1 \%$ & 0,12 \\
Nordeste & 1.015 .600 & $0,8 \%$ & $0,29^{\mathrm{a}}$ \\
Centro-oeste & 31.183 .625 & $23,2 \%$ & 0,89 \\
Sudeste & 18.145 .616 & $13,5 \%$ & $0,30^{\mathrm{a}}$ \\
Sul & 83.935 .529 & $62,4 \%$ & 0,50 \\
\hline Total & 134.466 .496 & $100 \%$ & 0,50 \\
\hline
\end{tabular}

* a: não diferem - valor de $\mathrm{p}=0,483$, demais $\mathrm{p}<0,05$

Tabela 9: Índice de ocorrência de condenações (IOC) médio por contaminações, contusão/lesão traumática, dermatose e celulite ao abate de aves por mês, Brasil, de 2006 a 2011

\begin{tabular}{|c|c|c|c|c|}
\hline Mês & $\begin{array}{l}\text { Contaminação } \\
\text { IOC médio* }\end{array}$ & $\begin{array}{l}\text { Contusão/lesão } \\
\text { traumática } \\
\text { IOC médio** }\end{array}$ & $\begin{array}{l}\text { Dermatose } \\
\text { IOC médio*** }\end{array}$ & $\begin{array}{c}\text { Celulite } \\
\text { IOC médio**** }\end{array}$ \\
\hline Jan & 18,0 & 15,4 & 7,2 & 5,0 \\
\hline Fev & 16,7 & 16,9 & 6,9 & 5,0 \\
\hline Mar & 17,8 & 15,2 & 7,1 & 4,8 \\
\hline $\mathrm{Abr}$ & 18,0 & 15,7 & 6,9 & 4,9 \\
\hline Mai & 18,1 & 15,6 & 7,0 & 5,1 \\
\hline Jun & 18,7 & 15,9 & 7,6 & 5,2 \\
\hline Jul & 18,4 & 15,8 & 8,5 & 5,3 \\
\hline Ago & 18,0 & 15,9 & 8,6 & 5,4 \\
\hline Set & 17,7 & 15,3 & 8,3 & 5,1 \\
\hline Out & 17,2 & 17,3 & 7,5 & 5,2 \\
\hline Nov & 17,8 & 14,8 & 7,1 & 4,9 \\
\hline Dez & 16,4 & 14,8 & 6,6 & 4,5 \\
\hline Total & 17,7 & 15,7 & 7,4 & 5,0 \\
\hline
\end{tabular}


Verificou-se que as principais causas de condenação relatadas neste estudo também são representativas em outros trabalhos realizados no Brasil e em outros países.

Observou-se que as causas de condenações ao abate com maior ocorrência no período de 2006 a 2011, neste estudo, foram contaminações $(1,8 \%)$, contusão/lesão traumática $(1,57 \%)$, dermatose $(0,74 \%)$ e celulite $(0,5 \%)$. Uma distribuição semelhante foi observada por Armendaris ${ }^{(10)}$, no período de 2003 a 2005, em que a contaminação, dermatose, contusão e celulite foram respectivamente as principais causas.

Os dados deste estudo diferem nas proporções de condenações de outros estudos realizados no Brasil. Segundo Paschoal et al. ${ }^{(13)}$, entre as aves condenadas totalmente em um abatedouro frigorífico no Paraná, as principais causas foram aspecto repugnante $(47,33 \%)$ e sangria inadequada $(23,09 \%)$; já entre as causas de condenação parcial, predominaram contusão/fratura $(54,38 \%)$ e celulite $(13,66 \%)$. No Rio Grande do Sul, Menconi et al. ${ }^{(11)}$ relataram principalmente aspecto repugnante $(0,48 \%)$ e contaminação $(0,23 \%)$. Em abatedouros no estado de Goiás, Santana et al. ${ }^{(15)}$ relataram, como principais causas de condenação, celulite $(4,25 \%$ e $0,91 \%)$, contusão/fratura/hematomas $(0,47 \%$ e $1,04 \%)$ e contaminação $(2,79 \%$ e $0,81 \%)$.

Em outros países, também foram verificadas diferenças na distribuição das condenações. AnsongDanquah ${ }^{(3)}$, no Canadá, no período de 1980 a 1985, relatou que as principais causas de condenação não foram relacionadas a doenças, apontando as contusões, contaminação e cianose/aves moribundas $(40,3 \%)$ como mais as prevalentes. As principais causas relacionadas a doenças foram artrite, aerossaculite, magreza e dermatite/celulite $(34,8 \%)$.

Já Herenda \& Jakel ${ }^{(6)}$ observaram que ascite $(0,26 \%)$, celulite $(0,26 \%)$, magreza $(0,22 \%)$ e cianose $(0,18 \%)$ foram as principais causas de condenação em aves criadas em manejo tradicional.

Adicionalmente, verifica-se grande volume e crescimento expressivo da ocorrência de causas de condenação não relacionadas a doenças, denominadas tecnopatias, como contaminação e lesões traumáticas. Estas também podem ser estudadas visando redução de sua ocorrência e, consequentemente, das perdas produtivas ${ }^{(6,10,14,16)}$. Neste contexto, as bases de dados nacionais podem ser utilizadas como uma importante fonte de informação.

No Brasil, estados como Paraná, Santa Catarina, Rio Grande do Sul, São Paulo, Minas Gerais e Goiás concentram os maiores parques industriais frigoríficos das regiões sul, sudeste e centro-oeste; portanto, a maioria dos trabalhos que avalia as causas de condenações ao abate foi desenvolvida nestas regiões, mas, além de ainda haver carência de mais trabalhos com este enfoque, alguns dados foram apresentados apenas em anais de congressos científicos, dificultando, assim, comparações a nível nacional. A região Centro-Oeste apresentou maior taxa de condenação por contaminação, celulite, bem como por todas as causas. As regiões sudeste e norte apresentaram maior taxa para contusão ou lesão traumática e a região norte a maior taxa para dermatoses.

As diferenças regionais na ocorrência das causas de condenação ao abate de aves devem ser mais estudadas, visando identificar, além dos principais fatores causais, as possibilidades de redução das taxas de condenações ao abate de aves considerando-se as regiões produtoras. Entre estas diferenças regionais, deve-se investigar melhor a influência das diferenças climáticas na sazonalidade de ocorrência de algumas causas de condenações.

Neste estudo, verificou-se que apenas a causa de condenação por dermatose, que é registrada ao abate como qualquer alteração na pele ${ }^{(4)}$, apresentou uma distribuição sazonal, com a maior ocorrência concentrada no período de inverno, nas principais regiões produtoras. As lesões cutâneas podem ter várias origens e estão relacionados principalmente com deficiências nas condições de manejo nas granjas como alta densidade de criação, excesso de umidade na cama e elevada concentração de amônia no ambiente ${ }^{(21-24)}$. Os cuidados de manejo na granja devem ser constantemente monitorados no período de inverno, frente às variações de temperatura observadas principalmente no sul e sudeste do país, para minimizar a ocorrência dos fatores que predispõem à dermatose.

Assim como neste estudo, Moretti et al. ${ }^{(5)}$ também não observaram distribuição sazonal das lesões traumáticas no Estado de São Paulo. Entretanto, Nijdam et al. ${ }^{(14)}$ relataram menor ocorrência de contusões nos meses de outono e primavera quando comparados aos meses de verão na Holanda. Sabe-se, entretanto, que a ocorrência de lesões traumáticas estão relacionadas ao método de apanha, tempo de transporte, tempo de espera, tipo de caixas de transporte e densidade das caixas ${ }^{(5,14,15,19)}$. 


\section{Conclusões}

As principais causas de condenação ao abate de aves são a contaminação, contusão/lesões traumáticas, dermatoses e celulite, com ocorrência de diferenças regionais e apresentação de comportamento sazonal apenas pelas dermatoses.

O SIGSIF é uma importante fonte de informação sobre as causas de condenação ao abate de aves e pode ser uma ferramenta útil para a avaliação dos fatores causais e proposição de medidas de prevenção ou mitigação de riscos. Estes dados estão rotineiramente coletados nos estabelecimentos sob Inspeção Federal, sendo importante aprofundar os estudos com base em dados secundários, visando entender a distribuição destes agravos, bem como levantar hipóteses a serem investigadas.

\section{Agradecimentos}

A todos os colegas do Departamento de Inspeção de Produtos de Origem Animal (DIPOA) do Ministério da Agricultura, Pecuária e Abastecimento (MAPA) e em especial à Divisão de Acompanhamento, Cadastro e Avaliação (DCA/DIPOA).

\section{Referências}

1. Brasil. Regulamento de inspeção industrial e sanitária de produtos de origem animal (RIISPOA). Decreto n 30.691 de 29 de mar de 1952, alterado pelo Decreto n 1.255 de 25 de jun de 1962. Diário Oficial da União, 7 jul 1952. [acesso 23 jul 2012]. Disponível em http://www.agricultura.gov.br/arq editor/file/ Aniamal/MercadoInterno/Requisitos/RegulamentoInspecaoIndustrial.pdf.

2. Brasil. Secretaria de Defesa Agropecuária. Regulamento Técnico da Inspeção Tecnológica e HigiênicoSanitária de Carne de Aves. Portaria SDA no 210 de 10 nov 1998. Diário Oficial da União, n 227, Seção I, de 26 nov 1998: 226-32. [acesso 23 jul 2012]. Disponivel em http://www.agricultura.gov.br/arq editor/file/ Ministerio/concursos/em andamento/portarias/port\%20210.doc.

3. Ansong-Danquah J. A survey of carcass condemnation at a poultry abattoir and its application to disease management. Can Vet J. 1987;28(1-2):53-6.

4. Palmeira-Borges V, Alessi AC, Rossi ODR. Cachexia in broilers at slaughterhouse. association of femoral head degeneration and caseous nephritis. Braz J Vet Pathol. 2014;7(3):144-14.

5. Moretti LA, Dias RA, Telles EO, Balian SC. Time series evaluation of traumatic lesions and airsacculitis at one poultry abattoir in the state of São Paulo, Brazil (1996-2005). Prev Vet Med. 2010;94(3-4):231-9.

6. Herenda D, Jakel O. Poultry abattoir survey of carcass condemnation for standard, vegetarian, and free range chickens. Can Vet J. 1994;35(5):293-6.

7. Ansari-Lari M, Rezagholi M. Poultry abattoir survey of carcass condemnations in Fars province, southern Iran. Prev Vet Med. 2007;79(2-4):287-93.

8. Drain ME, Whiting Tl, Rasali DP, D'angiolo VA. Warm weather transport of broiler chickens in Manitoba. I. Farm management factors associated with death loss in transit to slaughter. Can Vet J. 2007;48(1):76-80.

9. Whiting TL, Drain ME, Rasali DP. Warm weather transport of broiler chickens in Manitoba. II. Truck management factors associated with death loss in transit to slaughter. Can Vet J. 2007;48(2):148-154.

10. Bisaillon JR, Meek AH, Feltmate TE. An assessment of condemnations of broiler chicken carcasses. Can J Vet Res. 1988, 52(2): 269-276.

11. Menconi AL, Kuttappan VA, Hernandez-Velasco X, Urbano T, Matté F, Layton S, Kallapura G, Latorre J, Morales BE, Prado O, Vicente JL, Barton J, Andreatti Filho RL, Lovato M, Hargis BM, Tellez G. Evaluation of a commercially available organic acid product on body weight loss, carcass yield, and meat quality during preslaughter feed withdrawal in broiler chickens: a poultry welfare and economic perspective. Poult Sci. 2014;93(2):448-55.

12. Ferreira TZ, Sesterhenn R, Kindlein L. [Economic Losses of Main Causes of Condemnation of the 
Broiler Carcass in a Slaughterhouse under Federal Inspection on Rio Grande do Sul, Brazil]. Acta Sci Vet. 2012;40(1):1021. Portuguese.

13. Paschoal EC, Otutumi LK, Silveira AP. [Major reasons for condemnation in broiler slaughter in a slaughter house located in the northwest of Paraná, Brazil]. Arq. Ciênc. Vet. Zool. 2012;15(2):93-7. Portuguese.

14. Nijdam E, Arens P, Lambooij E, Decuypere E, Stegeman A. Factors influencing bruises and mortality of broilers during catching, transport, and lairage. Poult Sci. 2004;83(9):1610-5.

15. Santana AP, Murata LS, Freitas CG, Delphino MK, Pimentel CM. Causes of condemnation of carcasses from poultry in slaughter houses located in State of Goiás, Brasil. Cienc Rural. 2008; 38(9):2587-92.

16. Fletcher DL. Symposium: Recent advances in poultry slaughter technology. Poult Sci. 1999;78:277-81.

17. Oliveira ABA, Paula CMD, Capalonga R, Cardoso MRIC, Tondo EC. [Foodborne diseases, main etiologic agents and general aspects: a review]. Rev HCPA. 2010;30(3):279-85. Portuguese.

18. Silva RBTR, Naas IA, Moura DJ. Broiler and swine production: animal welfare legislation scenario. Sci. agric. 2009;66(6):713-20.

19. Rui BR, Angrimani DSR, Silva MAA. [Critical points in the pre-slaughter management of broiler: feed withdrawal, capture and catching, transport and lairage time in the plant]. Cienc Rural. 2011;41(7):1290-6. Portuguese.

20. Vieira FMC, Silva IJO, Barbosa Filho JAD, Vieira AMC, Rodrigues-Sarnighausen VC, Garcia DB. Thermal stress related with mortality rates on broilers' preslaughter operations: a lairage time effect study. Cienc Rural. 2011; 41(9):1639-44.

21. Garcia RG, Almeida Paz ICL, Caldara FR, Nääs IA, Bueno LGF, Freitas LW, Graciano JD, Sim S. Litter Materials and the Incidence of Carcass Lesions in Broilers Chickens. Braz J Poult Sci. 2012; 14(1): 27-32.

22. Lazarevica1 M, Resanovica1 R, Vucicevica1 I, Kochera A, Morana CA. Effect of feeding a commercial ammonia binding product De-Odorase ${ }^{\mathrm{TM}}$ on broiler chicken performance. Journal of Applied Animal Nutrition. 2014;2(8):1-6.

23. Olkowski AA, Wojnarowicz C, Chirino-Trejo M, Wurtz, BM, Kumor L. The Role of First Line of Defence Mechanisms in the Pathogenesis of Cellulitis in Broiler Chickens: Skin Structural, Physiological and Cellular Response Factors. J. Vet. Med. 2005, 52: 517-524

24. Allain V, Mirabito L, Arnould C, Colas M, Le Bouquin S, Lupo C,Michel V. Skin lesions in broiler chickens measured at the slaughterhouse: relationships between lesions and between their prevalence and rearing factors.Br Poult Sci. 2009,50(4):407-17. 